\title{
EFL supervisors' written feedback focus and language functions: a mixed methods study
}

\author{
Abate Demissie Gedamu* and Tesfaye Habtemariam Gezahegn
}

*Correspondence:

abachad22@gmail.com Department of English

Language and Literature,

College of Social Sciences

and Humanities, Arba Minch

University, P.O. Box 021, Arba

Minch, Ethiopia

\begin{abstract}
The objectives of this study were to examine the EFL supervisors' written feedback focus, and language functions at selected public universities in Ethiopia. To address the objectives of the study, qualitative and quantitative approaches with concurrent mixed methods design was adopted. 55 supervisees were randomly selected out of 205 for the questionnaire survey. Besides, four supervisors were selected for interviews. Moreover, feedback comments on five theses drafts were utilized as data sources. To decide the language functions and feedback foci, frequency counts and percentages were used. Nonetheless, content analysis was used to analyze the interview data. The results showed that thesis supervisors used the directive feedback language function most prevailingly over the expressive function. Besides, the result indicated there was no balance of praise, criticism, and suggestions in the provision of feedback comments. The supervisors largely focused on content knowledge, followed by genre knowledge, and then linguistic accuracy and appropriateness (forms), respectively. Based on the results, supervisors were recommended to write their feedback comments in helpful and constructive ways based on the needs and preferences of their supervisees for the development of writing skills.
\end{abstract}

Keywords: Effective feedback, Written feedback, Feedback focus, Feedback functions

\section{Introduction}

Tertiary education, particularly postgraduate studies, requires a great deal of writing as the courses require students to involve in numerous demanding writings. Thesis writing in particular demands a high academic writing calibre. Since English is a foreign language in Ethiopia, writing in English is a more daunting task than in any other context.

To develop the students' academic writing, teachers have to provide adequate and effective feedback on their students' writing (Hyland \& Hyland, 2001, 2003; Kumar \& Stracke, 2007). Thesis supervisees may not attain the level of academic writing expected of them without their supervisors' written feedback provision on their thesis works since effective feedback provides good learning experiences in writing (Hyland \& Hyland, 2006; Kumar \& Stracke, 2007; Leng, 2014). Accordingly, continuous written feedback on supervisees' theses drafts is the major source of learning and improvement upon which supervisees revise their drafts and close the gaps between their actual level and the standards expected of them (Giles et al., 2014; Kumar \& Stracke, 2007).

(c) The Author(s), 2021. Open Access This article is licensed under a Creative Commons Attribution 4.0 International License, which permits use, sharing, adaptation, distribution and reproduction in any medium or format, as long as you give appropriate credit to the original author(s) and the source, provide a link to the Creative Commons licence, and indicate if changes were made. The images or other third party material in this article are included in the article's Creative Commons licence, unless indicated otherwise in a credit line to the material. If material is not included in the article's Creative Commons licence and your intended use is not permitted by statutory regulation or exceeds the permitted use, you will need to obtain permission directly from the copyright holder. To view a copy of this licence, visit http:// creativecommons.org/licenses/by/4.0/. 
As effective written feedback is a form of communication, it should encourage and motivate the supervisees, acknowledge their efforts, and provide them with constructive criticisms in a less abrasive and more palatable tone, and offer specific suggestions on what they need to work on (Ghazal et al, 2014; Goodman \& Wood, 2004; Hattie \& Timperley, 2007). Besides, effective written feedback should have a focus and be written with the appropriate language function of the feedback.

The current study confirmed that there has been a felt niche on EFL thesis supervisors' written feedback language functions and focus on M.A students' thesis. The findings of this study may help EFL thesis supervisors to revisit their written feedback and offer constructive feedback that balances criticisms and encouragements to motivate them to write better and develop self-confidence in their writing and maintain close relationships with the supervisees. Besides, the findings of this study may also be helpful for supervisors to balance the focus of their feedback as thesis writing is not dependent on any single genre.

\section{Literature review}

\section{Language functions and focus of thesis supervisors' written feedback}

Effective communication of the feedback comments to the supervisees is vital as how to convey the message (language function) is also important as that of what to communicate (feedback focus). Studies showed there are potential problems as to how feedback is communicated in higher education (Bitchener et al, 2011) which included lack of specific suggestions on how to improve (Higgins et al. 2001), lack of clarity to interpret (Carless, 2006; Chanock, 2000), lack of focus of the feedback comments (Akin-Little et al., 2004; Lindemann, 2001). Among the various methods of effective communication of the feedback comments, language functions and feedback focus of thesis supervisors are the majors.

Concerning language functions of written feedback, a couple of studies showed the prevalence of direct feedback provision on students' errors (Gul et al., 2016; Lucero et al., 2018). Besides, Nurie (2018) carried a study on language functions of supervisors' written feedback to students' thesis at Bahir Dar University, Ethiopia. The data were collected from eight supervisors' written feedback comments. The result showed that the directive clarification language function was dominantly employed while expressive approval was ignored or rarely used. Besides, the findings revealed that directive instruction and expressive disapproval were almost equally applied next to directive clarification. This shows that supervisors ignored expressive approval while applying expressive disapproval from the directive function category. In other words, the feedback is dominantly criticism devoid of positive comments (praise). This implies that there is no balance of praise, criticism, and suggestions in the provision of feedback comments.

Similarly, Ghazal et al. (2014) showed that teachers critiqued students' work without offering suggestions and hence the comments lacked a balance of praise, criticism, and suggestions. Moreover, the feedback comments were found overcrowded with several symbols for criticism with no elaboration or direction to the students for improvement. In the same vein, Lee (2009) disclosed that teachers mostly provide critical feedback on weaknesses ignoring the strengths of the work. Furthermore, it was indicated that teachers used to capitalize on students' errors without offering supportive suggestions on how 
to improve their works. Nevertheless, studies suggest effective written feedback should balance both the strengths and weaknesses of the students' writings (Ghazal et al., 2014; Hyland \& Hyland, 2001; Weaver, 2006) worded in a soft tone with suggestions and reflective questions (Ghazal et al., 2014).

The other very essential aspect of effective written feedback is the focus of the feedback supervisors provide to their supervisees. About this issue, Nurie (2018) carried a study on the focus of supervisors' written feedback to students' thesis at Bahir Dar University, Ethiopia. The data were collected from written feedback comments of eight supervisors. The findings showed written feedback on the genre of the thesis, content knowledge, and linguistic accuracy and appropriateness were frequently offered in priority, respectively. Other studies (Gul et al., 2016; Lucero et al., 2018) disclosed that teachers used to place excessive emphasis on local and superficial issues at the expense of other semantic, rhetorical or pragmatic aspects. Nevertheless, in Ghazal et al's (2014) study, most feedback comments focused on the content while still, some emphasized form and style. Lee (2009) also showed that the feedback teachers usually give to their students focuses on form.

On the same issue of concern, Bitchener and Basturkmen (2010) investigated the feedback focus of supervisors on 35 supervisors in the fields of Humanities, Mathematics, and Commerce at six New Zealand universities. The data were gathered through questionnaires, interviews, and samples of the feedback given on thesis drafts. The findings showed that feedback on gaps in the content covered was the most frequent area with a particular focus on theoretical understanding and coverage. Besides, feedback on building an argument coherently and cohesively was also found in the area of attention in the feedback provision.

\section{Statement of the problem}

The studies reviewed above ought to be re-reviewed in terms of their perspectives, study focus, and tools employed to identify and justify the felt gaps. Accordingly, some of the studies were done on written feedback from teachers' perspectives (Gul et al., 2016; Lucero et al., 2018; Hyland \& Hyland, 2001). Others viewed written feedback on students' assignments from both teachers' and students' perspectives (Ghazal et al., 2014; Mulliner \& Tucker, 2015). The study by Nurie (2018) emphasized on focus and language functions of supervisors' written feedback to M.A students' thesis while Kumar and Stracke (2007) stressed on language functions of written feedback on the Ph.D. thesis. Concerning tools employed, most studies used a questionnaire and focus group discussions or interviews. However, some studies applied written feedback comments as the only tool (Iqbal et al., 2014; Kumar \& Stracke, 2007; Lucero et al., 2018; Nurie, 2018). On the other hand, Ghazal et al. (2014) employed feedback comments and student interviews while Hyland and Hyland (2001) utilized feedback comments along with teacher interviews and think-aloud protocol.

Limited studies were done on EFL thesis supervisors' written feedback language functions and focus on M.A students' thesis work (Bitchener \& Basturkmen, 2010; Kumar \& Stracke, 2007; Nurie, 2018). The study conducted by Kumar and Stracke (2007) and Nurie (2018) used only feedback comments as a tool for data collection although multiple tools could be used from different perspectives on large participants. Thus, it seems 
that there is a scarcity of studies to understand the issue. Therefore, the present study was conducted to examine EFL thesis supervisors' written feedback to focus and language functions to M.A students' thesis in public universities in Ethiopia.

Specifically, this study aimed to answer the following two specific objectives: (1) examine the focus of supervisors' written feedback on supervisees' thesis, and (2) inspect the language functions of written feedback comments the thesis supervisors provide to their supervisees'

\section{Theoretical framework}

Understanding the theoretical framework underlying written feedback provision is essential to offer effective feedback and engage the supervisees actively in the learning process. As to the constructivist theory, language learning is an active process of knowledge construction in which learners are actively engaged in the learning process with information and feedback from capable individuals that includes teachers, peers, and others (Hattie \& Timperley, 2007). Among the various learning platforms, written feedback is one and is built on the Speech Act Theory of Searle (1969) and the language function theory of Holmes (2001). The two theories are supposed to provide a clear rationale to categorize feedback as a form of communication between the provider and the receiver of the feedback.

Although Searle (1969) divided the Speech Act Theory into six categories, the directive and expressive were considered in this study as they are commonly related to written feedback. The directive is again subdivided into directive-clarification and directiveinstruction (Kumar \& Stracke, 2007) while the expressive function is sub-classified into praise, criticism, and suggestion (Hyland \& Hyland, 2001). As to written feedback focus, Bitchener and Basturkmen's (2010) categorization was used. The categories include three major areas: content knowledge (its accuracy, completeness, and relevance), genre knowledge (the functions of different parts of a thesis), and linguistic accuracy and appropriateness.

Therefore, we adopted a mixed theoretical framework that combined the Speech Act Theory of Searle (1969) and the language function theory of Holmes (2001). As well, Bitchener and Basturkmen's (2010) categorization of feedback focus was assumed as a framework in this study. These theories give a lucid explanation to classifying feedback as a form of communication between the feedback providers and the receivers and may serve as the framework to embrace mutually the variables we dealt with in this study.

\section{Materials and methods}

\section{Context of the study}

This study was conducted on written feedback the thesis supervisors offer to their supervisees in Teaching English as a Foreign Language (TEFL) while conducting their M.A thesis. The study took place in four public universities in Ethiopia. Among the universities of Ethiopia, Arba Minch University, Wolayeta Sodo University, Hawassa University, and Dilla University were selected for this study due to their relative proximity to the researchers' workplace, Arba Minch. The data were collected in 2020 between January and October. 
To understand thesis supervision in the study area context, it seems important to have a glance at the culture of thesis supervision in a general and the supervisor-supervisee relationship in particular. Although there is a scarcity of studies on the issues, it is attempted to contextualize thesis supervision culture and supervisor-supervisee relationship. To begin with, Zewdu (2012) conducted a Ph.D. dissertation on the research culture of the TEFL program of Addis Ababa University (AAU). The results showed that the relationships between supervisors and supervisees were less friendly and less collegial which, in turn, affected the quality of the dissertation and the commitment of the candidates to carry out their studies. Besides, candidates reported the supervisors to provide only written feedbacks and rarely invite them for face-to-face discussions, and hence the supervisees do not get the chance to put forward their research-related concerns. Moreover, the study revealed that the supervision is mostly a unidirectional flow of ideas from supervisors and the students' are largely passive recipients.

Nurie (2018) also carried a study on supervisors' written feedback to students' theses at Bahir Dar University, Ethiopia. The result showed that the directive clarification language function was dominantly employed while expressive approval was ignored or rarely used. To put it in other words, the feedback nature of the supervisors is dominantly criticism devoid of positive comments (praise) that may show the unfriendly behavior of the supervision and distance between the supervisors and supervisees.

Abate (2018) conducted a study on TEFL graduate supervisees' perception of their thesis supervisors' supervisory styles. The results disclosed that the supervisees perceived their supervisors as displaying contractual and laissez-faire styles while the pastoral style was not perceived. The missing of the pastoral style of supervision shows the supervisors do encourage and motivate the supervisees as a vital part of supervision. This implies the supervisors are committed to providing only the academic feedback on the thesis ignoring the psychological support; thus, there is a distance between supervisors and supervisees in the supervisory process.

It seems apparent that there is a distance between supervisors and supervisees. Besides, the relationships between supervisors and supervisees are less friendly as the supervisors provide written feedbacks dominated by criticisms and rarely invite them for face-to-face discussions. Thus, the culture of thesis supervision and supervisorsupervisee relationship do not seem attractive to cultivate the supervisees' potentials of academic writing to solve societal problems.

\section{Research design}

The objectives of this study were to examine EFL supervisors' focus and language functions of written feedback at some selected public universities. To address these objectives, a convergent (concurrent) mixed methods design was adopted to understand the research problem through collecting quantitative and qualitative data simultaneously (Creswell, 2009). It is believed that the use of both the quantitative and the qualitative approaches together capitulates a better understanding of the research problem than either approach alone and improves the validity and credibility of the results (Creswell \& Plano Clark, 2007; Saldana, 2011).

Therefore, the quantitative approach was sought to generate quantitative data from the supervisees through a questionnaire on their supervisors' written feedback language 
functions. Besides, the in-text quantitative data were collected from written feedback the supervisors provided to their supervisees to examine the feedback functions and focus of the supervisors. In contrast, qualitative data was acquired through interviews from supervisors on their written feedback language functions and focus. The interview data allowed in-depth data on the written feedback functions and focus although the interviewees were few individuals.

Although the quantitative and qualitative data were collected concurrently, each was analyzed separately. Yet, the results obtained through both approaches were integrated into the discussion section and were compared to determine whether they supported or contradicted each other and interpreted to get a better insight into the issues of the study.

\section{Data sources}

Four EFL thesis supervisors and fifty-five supervisees selected from the four universities were the data sources. Besides, in-text feedback comments the supervisors provided to their supervisees were the other data sources. The supervisees were addressed through a questionnaire while interviews were conducted with the supervisors to obtain in-depth data on their written feedback language functions and focus. Although written feedback comments are provided by supervisors and they are almost the sole sources, it seems essential to incorporate supervisees' views on their supervisors' feedback focus and language function coupled with the supervisors.

\section{Instruments}

This study aimed to explore the feedback focus and language functions of supervisors' written feedback on supervisees' thesis. To address these objectives, a questionnaire, interviews, and in-text feedback comments on thesis drafts were utilized.

The purpose of the supervisees' questionnaire was to obtain quantitative data on their supervisors' feedback focus. A close-ended questionnaire was prepared based on the literature on a five-point Likert scale that ranged from never (1), rarely (2), sometimes (3), often (4), and always (5). The questionnaire constituted of 15 items in three sections. The first section covered $(n=6)$ items on linguistic accuracy and appropriateness (form), and the second and the third sections formed content knowledge $(n=5)$ items and genre knowledge $(n=4)$ items, respectively. The reliabilities of the sections were also checked. The Cronbach alpha value of 0.91 was obtained for linguistic accuracy and appropriateness while Cronbach alpha values of 0.88 and 0.89 were gained for content knowledge and genre knowledge, respectively. These indicated that the dimensions for feedback focus are highly reliable for data collection.

Semi-structured interview questions were utilized to intensively probe supervisors' views of feedback language functions and focus on their feedback practices. Thus, the purpose of the interview was to generate elaborated in-depth information on the issue mentioned. To this effect, face-to-face individual interviews were held with selected supervisors. The interview lasted from 15 to $17 \mathrm{~min}$ with each of the supervisors.

To generate valuable data about supervisors' feedback focus and language functions, the in-text feedback comments on supervisees' theses drafts were used. To this effect, the intext feedback comments on five theses were selected randomly from the four universities 
assuming adequate data would be obtained from them. The in-text written feedback comprised of all comments offered by the supervisor provided in the margin of the text most of the time. Each comment, phrase, or word that communicated a single message to the supervisee was taken as one piece of communication.

\section{Methods of data analysis}

The objectives of this study were to examine EFL supervisors' written feedback focus, and language functions. The data from the written text was arranged and coded into categories. To this effect, the focus of written feedback comments was grouped as content knowledge (if comments are on the accuracy, completeness, and relevance of thoughts and clarity of ideas), linguistic accuracy, and appropriateness (if comments highlighting grammar, punctuation, tenses, surface structure errors, and word choices), and writing genre (if comments are on the functions of different parts of a thesis which includes literature synthesis, argument building, reflective writing, and referencing style, etc.) according to Bitchener and Basturkmen (2010) categorization of feedback focus.

The categorization and organization of feedback language functions into the directive and expressive functions and the subcategories were adapted from earlier studies (Hyland \& Hyland, 2001; Kumar \& Stracke, 2007). As to Kumar and Stracke (2007), directive feedback is ordering the supervisees to do something and is sub-categorized into clarifications and instructions. On the other hand, the expressive function of feedback is conveying feelings and is comprised of praise, criticism, and opinion/suggestion. It is comprised of praise/ approval, criticism/disapproval, and opinion/suggestion (Hyland \& Hyland, 2001; Kumar \& Stracke, 2007). Consequently, feedback comments which appreciate or credit student work was coded as praise, while comments that show dissatisfaction or negative were coded as criticism, and comments that give ways to do the work were coded as a suggestion (Hyland \& Hyland, 2001).

To develop an appropriate categorization and coding, the researchers tried the categorization numerous rounds individually and then in pairs. The comments were, therefore, double-coded to ensure the credibility of the coding. The organized data obtained through supervisees' questionnaires and in-text written feedback comments on the thesis were quantified and organized into frequency counts and percentages.

The data obtained through interviews from the supervisors were also coded and organized into the directive and expressive functions of language and their sub-categories, and feedback focus. As the principal aim of the interview was to describe the language functions of written feedback, content analysis was found suitable to analyze the data. Accordingly, the interview data were then analyzed through the qualitative description to address the language functions and focus of written feedback of the supervisors.

\section{Results}

This section introduced results on thesis supervisors' feedback language functions and focus on the supervisees' thesis. 
Table 1 Feedback distribution based on speech act functions

\begin{tabular}{llc}
\hline Function & Number & Percent \\
\hline Directive & 397 & 74.6 \\
Expressive & 135 & 25.4 \\
Total & 532 & 100 \\
\hline
\end{tabular}

Table 2 Supervisors' feedback language functions on students' theses

\begin{tabular}{lcc}
\hline Function & Number & Percent \\
\hline Directive clarification & 221 & 41.5 \\
Direct instruction & 135 & 25.4 \\
Expressive approval & 3 & 0.6 \\
Expressive disapproval & 88 & 16.5 \\
Expressive suggestion & 85 & 16 \\
Total & 532 & 100 \\
\hline
\end{tabular}

\section{Quantitative data analysis}

\section{Supervisors' feedback functions}

This subsection examines thesis supervisors' feedback language functions in their feedback comments to the supervisees. To this effect, on-script feedback comments, and interviews with the supervisors were employed. The data have been analyzed and presented below.

\section{On-scripts feedback functions}

As shown in Table 1, the written feedback students received on their theses are directive and expressive. Sums of 532 feedback comments were found in the written drafts of the students. Among which, 397 (74.6) written feedback is directive which urges the receiver for action while the expressive feedback category accounts for 135 (25.4). Thus, it seems that the supervisors use the directive function most dominantly in their feedback provision.

Table 2 shows the sub-categories of directive and expressive feedback language functions. The results (Table 2) indicated that supervisors' feedback on students' theses was dominantly directive-clarification 221 (41.5\%) followed by directive-instruction 135 (25.4\%). Directive-clarification feedback requests the students for the clear elucidation of ideas in the paper for direction and revision. Some of the directive-clarification common in the comments comprise: 'how?', 'what do you mean?', and 'evidence?? How do you relate these (teachers' traditional teaching and students' reading) to VLS? '.

The second most commonly offered feedback was directive-instruction feedback. This feedback type gives direction to the students to make necessary amendments in the texts. Among the many feedback comments of directive-instruction provided in the theses, some of them which may exemplify the entire are: 'please check spelling, 'follow SGS format for the cover page and title page,' 'put this in its right place, not here', and 'consistently (in all) capitalize initial letters of content words in titles and sub-titles.' 
Expressive-disapproval feedback was the third frequently provided feedback which accounts for 88 (16.5\%) of the total comments. Some of the expressive-disapproval feedback comments the students received includes: 'this can't be a sound justification', 'faulty parallelism,' 'this is inappropriate citation; no two names should be used like this', 'your background looks like literature review, not study background,' 'it is also too long and lacks focus', and 'your questionnaire as an instrument lacks a description.

The expressive suggestion was the fourth that took $85(16 \%)$ of the total comments. For instance, some of the expressive-suggestion comments provided in the theses of the students are: 'you need to relate your research find with previous research findings. You should show the differences and the similarities between the findings of your study and the previous studies', 'try to shorten the background by focusing on only the pertinent issues which have a direct bearing on your title', and 'you need to specifically state what methods you employed to ensure the validity of each tool's data; then state the same about reliability.'

On the contrary, expressive-approval feedback was insignificant $3(0.6 \%)$ in the written feedback comments the students received. These include: 'this is a good objective'; 'you already started talking about similar local studies. Keep on doing this', and 'the background seems good.' This implies that the provision of negative comments (criticisms) seems to be overriding in the feedback comments as compared to opinions for improvement and acknowledgment of the strength of students' attempts.

\section{Supervisors' feedback focus}

This subsection examines thesis supervisors' feedback focus on supervisees' theses. To this effect, on-script feedback comments, interviews with the supervisors, and a questionnaire to the supervisees were used. The data have been analyzed and presented below.

\section{Supervisees' views of their supervisors' feedback focus}

Table 3 depicts that six attributes were used to measure thesis supervisees' views of their supervisors' feedback focus on their theses. The majority of the supervisees $(40.4 \%$ and $27.5 \%$, on average) replied that their supervisors' feedback focuses are on linguistic accuracy and appropriateness as frequently as 'often' and 'always', respectively. Specific to the attributes of linguistic accuracy and appropriateness, a

Table 3 Linguistic accuracy and appropriateness

\begin{tabular}{llccccc}
\hline \multirow{2}{*}{ Items } & \multicolumn{2}{l}{ Number (Percent) } & & \\
\cline { 3 - 6 } & & Always & Often & Sometimes & Rarely & Never \\
\hline 1 & Appropriateness of word choice & $18(32.7)$ & $21(38.2)$ & $11(20)$ & $5(9.1)$ & - \\
2 & Appropriateness of voice & $16(29.1)$ & $27(49.1)$ & $7(12.7)$ & $2(3.6)$ & $3(5.5)$ \\
3 & Grammatical accuracy & $9(16.4)$ & $19(34.5)$ & $15(27.3)$ & $9(16.4)$ & - \\
4 & Coherence and cohesion & $13(23.6)$ & $23(41.8)$ & $15(27.3)$ & $4(7.3)$ & - \\
5 & Development of ideas & $17(30.9)$ & $24(43.6)$ & $10(18.2)$ & $4(7.3)$ & - \\
6 & Stance in the thesis work & $17(30.9)$ & $18(32.7)$ & $10(18.2)$ & $7(12.7)$ & $3(5.5)$ \\
& Total & $90(27.5)$ & $132(40.4)$ & $68(20.8)$ & $31(9.5)$ & $6(1.8)$ \\
\hline
\end{tabular}


Table 4 Content knowledge

\begin{tabular}{llrrrrr}
\hline \multirow{2}{*}{ Items } & \multicolumn{2}{c}{ Number (Percent) } & & & \\
\cline { 3 - 6 } \cline { 3 - 6 } & & Always & Often & Sometimes & Rarely & Never \\
\hline 7 & Gaps in the content and coverage & $10(18.2)$ & $22(40)$ & $14(25.5)$ & $9(14.4)$ & - \\
8 & Irrelevance of issues in the research & $6(10.9)$ & $22(40.0)$ & $15(27.3)$ & $12(21.9)$ & - \\
9 & Gaps in the justification of arguments & $8(14.5)$ & $19(34.5)$ & $22(40.0)$ & $6(10.9)$ & - \\
10 & Theoretical frameworks of the thesis & $12(21.8)$ & $17(30.9)$ & $14(25.5)$ & $12(21.8)$ & - \\
11 & Gaps in coverage of new literature & $7(12.7)$ & $20(36.4)$ & $17(30.9)$ & $11(20)$ & - \\
& Total & $43(15.6)$ & $100(36.4)$ & $82(29.8)$ & $50(18.2)$ & 0 \\
\hline
\end{tabular}

Table 5 Genre knowledge

\begin{tabular}{lllllll}
\hline \multirow{2}{*}{ Items } & \multicolumn{3}{l}{ Number (Percent) } & \\
\cline { 3 - 6 } \cline { 3 - 5 } & & Always & Often & Sometimes & Rarely & Never \\
\hline 12 & Placement of units or topics of contents in the thesis & $14(25.5)$ & $20(36.4)$ & $13(23.6)$ & $8(14.5)$ & - \\
13 & $\begin{array}{l}\text { The rationale for including particular content in a } \\
\text { particular part-genre }\end{array}$ & $6(10.9)$ & $27(49.1)$ & $16(29.1)$ & $6(10.9)$ & - \\
14 & $\begin{array}{l}\text { Functions and contents of different parts of the } \\
\text { thesis } \\
15\end{array}$ & $10(18.2)$ & $20(36.4)$ & $19(34.5)$ & $6(10.9)$ & - \\
$\begin{array}{l}\text { The use of other samples for contents of different } \\
\text { parts of the thesis } \\
\text { Total }\end{array}$ & $14(25.5)$ & $21(38.2)$ & $9(16.4)$ & $7(12.7)$ & $4(7.3)$ \\
\hline
\end{tabular}

significant number of the supervisees indicated that their supervisors were less concerned to focus on grammatical accuracy, and coherence, and cohesion as compared to the four attributes. Supervisors' feedback focus on the contents of supervisees' theses is presented below.

Table 4 shows five indicators that were used to measure supervisees' views of their supervisors' feedback focus on their thesis works. The majority of the supervisees $(36.4 \%$ and $15.6 \%$, on average) demonstrated that their supervisors' feedback focuses are on the content of the thesis as recurrently as 'often' and 'always', respectively. However, the data indicated that still, large percentages of the respondents rated that their supervisors' feedback focus on the content of their thesis works ranges between sometimes (29.8\%) and rarely (18.2\%). Concerning particular indicators of feedback focus on content, an undeniable percent of the respondents showed their supervisors rarely focus on relevance/irrelevance of issues, theoretical framework, and gaps in the coverage of the literature. Supervisors' feedback focus on the genre of theses is presented below.

As shown in Table 5, four indicators were used to measure supervisees' views of their supervisors' feedback focus on their thesis works. The majority of the supervisees (40\% and $20 \%$, on average) revealed that their supervisors' feedback focuses are on the genre as regularly as 'often' and 'always', respectively. Nevertheless, there are still large percentages of supervisees who rated their supervisors' feedback focus on genre knowledge as frequently as sometimes (26\%) and rarely (12.3\%). On indicators of feedback focus on genre, the supervisees have proven that their supervisors' focus on the rationale to including particular content in a particular part-genre, and functions and contents of different parts of the thesis as often as sometimes and rarely. 
In conclusion, the average percentage in the tables above showed that the supervisees perceived that these supervisors focused dominantly on linguistic accuracy and appropriateness, followed by genre, and content respectively as frequently as 'always' and 'often'. However, it seems essential to examine supervisors' feedback focus on supervisees' theses to make an accurate conclusion of the issue. Therefore, supervisors' feedback focus on supervisees' theses is presented in Table 6 below.

\section{On-scripts data analyses on feedback focus}

Supervisors' written feedback focus on students' theses was collected from in-text comments of the theses. The data were collected and organized into content knowledge (its accuracy, completeness, and relevance), genre knowledge (the functions of different parts of a thesis), and linguistic accuracy and appropriateness. Table 6 shows content knowledge (66.5\%) was the most frequently observed written feedback which requires students' conceptual understanding, accuracy, completeness, and relevance. A few of these comments, as illustration include: 'indicate how your work is different from others?', 'not clear?', and 'can this be a reason for the sampling?'

The second most frequent feedback focus, though it is one-third of content knowledge, was genre knowledge (20.5\%) which deals with referencing and citations, the functions of different parts of a thesis, and the relevance and appropriateness of the thesis for scientific research. Some of these include: 'do you think this discussion is appropriate here?', 'bring the discussion here', and 'it must be the title of the journal which should be bold.'

The third frequent feedback focus was on linguistic accuracy and appropriateness (13\%). A few exemplars of the written comments asked students to revise, edit, or use the correct and formal language which include: 'this is not an appropriate term in research,' 'check the completeness of your sentence,' 'check language?', and 'not parallel???' are some to mention.

In conclusion, it seems that the majority of the comments focus on content knowledge, followed by genre knowledge, while a limited percentage of feedback focuses on linguistic accuracy and appropriateness.

\section{Qualitative data analysis}

\section{Interview data analysis on feedback focus and functions}

Teachers were interviewed on the focus and language functions of feedback comments. Based on the interview data, focus on contents of the thesis was observed as the overriding theme although the supervisors claimed they sometimes focus on other aspects as well. Concerning this, one of the interviewed supervisors underscored that he pays

Table 6 Supervisors' feedback focus on students' theses

\begin{tabular}{lcc}
\hline Feedback type & Number & Percent \\
\hline Content knowledge & 301 & 66.5 \\
Genre knowledge & 93 & 20.5 \\
Linguistic accuracy and appropriateness & 59 & 13 \\
Total & 453 & 100 \\
\hline
\end{tabular}


attention to content, genre, and linguistic accuracy and appropriateness though he gives more attention to content and noted the following:

I mainly focus on organization, the relevance of concepts included (content), and formatting issues. Sometimes, I also consider mechanics and diction as well. I often give due emphasis on content and organization as they are the most important pillars of the learners' written research report.

Describing the focus of feedback comments he offers to his supervisees, the second interviewee noted:

I focus on all parts of the candidates' research work but I give special attention to the links among the research title, the stamen of the problem, the objectives, the methodology section, and the analysis section with the major findings. My reason for doing this is that focusing on these parts may give me the picture of the research; how things are woven together in a thread-the flow of the entire research work.

The third interviewed supervisor believes that he focuses on aspects he thinks are essential. The specific aspects he focuses on include adequacy and relevance of contents, word choices and organizational issues, writing styles, and conventions. This supervisor seems that he is eclectic in his focus on feedback comments.

The last interviewed supervisor emphasized that effective feedback should indicate where the problems lie and how these problems should be addressed. He further noted that supervisors' written feedback comments are meant for improving supervisees' work and hence they should use them as much as possible. Accordingly, he mentioned that he focuses on content, genre, and linguistic accuracy and appropriateness although he pays more attention to content in his feedback comments. The interviewee additionally noted the following:

I focus on all aspects of a thesis while giving feedback comments. Truly speaking most of the time I focus on content. But this does not mean I ignore other aspects. For instance, I suggest students adhere to the school of graduate studies (SGS) guidelines of my university. Besides, I give due attention to the language aspect as well though I give more attention to that of contents.

Based on the interview data, the directive clarification language function was observed as the overriding theme although the supervisors claimed they use other language functions in their feedback provision as well. Regarding this issue, the interviewed supervisors replied that they use directive language in their feedback comments. Specifically, they mentioned that they apply directive clarification most of the time. Besides, they claimed that they use directive instruction feedback comments sometimes as well. In the elaboration of these, one of the interviewees noted the reason behind his choice for directive clarification over directive instruction, and noted:

I use both [directive clarification and directive instruction] though I tend to use directive clarification in my written feedback most of the time. The reason for this is that this [directive clarification] kind of feedback comment is very much important to encourage students to search for knowledge or to create insight learning (which is important to discover solutions to problems). Besides, it gives the candidates to see 
their works and to revisit them in light of the comments.

The other interviewed supervisor replied that his feedback language most of the time is that of directive clarification which requests the supervisees to elaborate and substantiate what they are writing. Also, he reported he uses expressive suggestions to give them room to revisiting their work as well rather than praise or criticisms. Moreover, he mentioned that he sometimes suggests the resources useful to address the comments given.

However, the interviewees mentioned that they do not often use expressive approval and suggestions though they abundantly apply criticisms in their feedback comments. As to his use of expressive suggestion feedback comments, one of the interviewees stated he uses suggestions rarely when he feels that the learner is somehow confused.

\section{Discussion}

To examine thesis supervisors' language functions in their feedback comments to the supervisees, on-script feedback comments and interviews with the supervisors were employed. The results obtained from both on-script feedback comments disclosed that the supervisors generally used the directive feedback language most dominantly in their feedback provision as compared to expressive feedback. The interview results as well revealed that the supervisors apply the directive feedback categories as contrasted to expressive feedback types. Thus, the findings reveal that the supervisors seem to apply the directive feedback language mainly in their feedback provision over the expressive feedback language function. The findings are consonant with previous works in which directive feedback has been found pervasively in the provision of feedback (Gul et al, 2016; Leng, 2014; Lucero et al., 2018; Nurie, 2018). Conversely, the study done by Kumar and Stracke (2007) showed that the directive and expressive feedback functions shared equal status in the feedback provision of the supervisors. It is suggested that directive feedback comments are greatly helpful for supervisees in giving them a sense of direction for revising their writing (Hattie \& Timperley, 2007; Hyland \& Hyland, 2006; Ogede, 2002), particularly in EFL contexts.

Specific to the feedback language functions sub-categories, the results gained from onscript feedback comments showed that the supervisors' feedback comments were prevailingly directive clarification followed by directive instruction. The interview results also showed the supervisors used to offer directive clarification feedback language function to requests the supervisees to elaborate and substantiate what they are writing most of the time even if they sometimes use directive instruction feedback comments as well. Previous work also corroborates the present findings that directive clarification language function was dominantly employed over directive instruction (Nurie, 2018). On the contrary, the study carried out by Leng (2014) showed that directive instruction feedback comments dictate over directive clarification in the provision of supervisors' feedback.

As to the expressive categories, the expressive-disapproval (criticisms) and expressivesuggestion feedback comments were almost equally the third frequently provided feedback comments. In contrast, expressive approval (praise) was found rare in the written feedback comments the supervisees received. The interview results also indicated the supervisors use expressive suggestion feedback comments to let the supervisees have room to revisit their work and expressive-disapproval (criticisms). Besides, the interview results the supervisors do not often use expressive approval (praise) language function in 
their feedback comments. The findings depicted that there was no balance of praise, criticism, and suggestions in the provision of feedback comments. The current findings are similar to the early works in the area which indicated that the feedback comments are dominantly criticism devoid of positive comments or praises (Leng, 2014; Nurie, 2018). Similarly, Ghazal et al. (2014) showed that teachers critiqued students' work without offering suggestions and hence the comments lacked a balance of praise, criticism, and suggestions. In the same vein, Lee (2009) disclosed that teachers mostly provide critical feedback on weaknesses ignoring the strengths of the work. Moreover, it was indicated that teachers used to capitalize on students' errors without offering supportive suggestions on how to improve their works.

Nevertheless, the study that was done by Hyland and Hyland (2001) showed that praise was most frequently employed in the feedback provision. The criticisms and suggestions were mitigated with the use of hedging devices like question forms and personal acknowledgment. Consequently, it was divulged that the students failed to understand their teachers' comments as the comments became highly indirect as the result of over mitigation of the feedback comments.

Researchers suggest that the tone of feedback should be neither too mitigated (soft) nor too critical. If criticisms and suggestions are highly mitigated with the use of hedging devices, the supervisees may not understand the extremely indirect comments of the supervisors as the result of over mitigation of the feedback comments (Hyland \& Hyland, 2001). Similarly, the duo concluded that critical feedback with too much criticism could not be useful as supervisees may not pay attention to them for revision. To this effect, effective feedback should balance both the strengths and weaknesses of the students' writings (Ghazal et al., 2014; Hyland \& Hyland, 2001; Toledo, 2013; Weaver, 2006).

To scrutinize thesis supervisors' feedback focus on supervisees' theses, on-scripts feedback comments, interviews with the supervisors, and a questionnaire to the supervisees were used. The results obtained from the supervisees' questionnaire indicated the supervisees perceived their supervisors' focused prevailingly on linguistic accuracy and appropriateness, followed by genre, and content knowledge, respectively as frequently as 'always' and 'often'. On the contrary, the outcomes acquired from on-script feedback comments and interviews revealed that the feedback comments supervisors provide to their supervisees were principally focused on content knowledge, followed by genre knowledge, and then on linguistic accuracy and appropriateness, respectively. Since onscript feedback comments are first-hand and are real shreds of evidence to judge the gravity of feedback focus of the supervisors, it seems that the feedback comments the supervisors provide to their supervisees were largely focused on content knowledge, followed by genre knowledge, and then linguistic accuracy and appropriateness (forms), respectively. To conclude, the feedback comments the supervisors provide to their supervisees are prevailingly focused on content knowledge.

The present findings are concurrent with the previous works in the area which showed that feedback comments focused on gaps in the content covered were the most frequent followed by a focus on either genre of the thesis or linguistic accuracy and appropriateness (Bitchener \& Basturkmen, 2010; Ghazal et al., 2014; Kumar \& Stracke, 2007; Hyatt, 2005; Hyland \& Hyland, 2001; Magno \& Amarles, 2011). On the opposite, some 
empirical works also showed that teachers' feedback comments focused mainly on linguistic accuracy and appropriateness (forms) at the expense of other aspects (Gul et al,, 2016; Lee, 2009; Lucero et al., 2018). Besides, the study done by Nurie (2018) disclosed that written feedback on the genre of the thesis, content knowledge, and linguistic accuracy and appropriateness were frequently offered in priority, respectively.

Studies on students' needs and preferences of written feedback also agree with the findings of the current study that supervisees usually preferred feedback on content the most followed by preferences for either genre of the thesis or linguistic accuracy and appropriateness (Ghazal et al, 2014; Nurie, 2020). Besides, Hattie and Timperley (2007) affirmed that feedback is more effective when it provides information on the content. This implies that the feedback comments supervisors provide to their supervisees should base on the needs and preferences of the supervisees if the feedback comments are sought to develop the writing competence of the supervisees in the EFL context in particular.

\section{Conclusions and implications}

The results of the study showed that the theses supervisors used to offer directive feedback most prevailingly in their feedback provision more than the expressive feedback. In particular to the sub-categories of the feedback language functions, the feedback comments the supervisees received were mainly directive clarification followed by directive instruction. To put it differently, the supervisors favoured asking for additional information from the supervisees for a clearer elucidation instead of offering directions on explicit issues for improvement. This further suggests that the supervisors' feedback comments are more reflective questions that provide the supervisees opportunity to reflect as compared to the directive instruction which requests actions for changes. This implies that supervisors are scaffolding the supervisees to clarify their points through reasoning and argument and revisit their works. In other words, the supervisors are assisting their supervisees to develop higher levels of writing competence of clarifying their themes through supporting pieces of evidence and arguments.

Besides, the expressive-disapproval (criticisms) and expressive-suggestion feedback comments were almost equally the third frequently provided feedback comments while the expressive-approval (praise) was rare in the written feedback comments the supervisees received. This entails that the supervisors are offering supportive and informative feedback suggestions on what and how to improve their works along with critical feedback on weaknesses although the strengths of their works were almost ignored in the feedback comments. This implies that praise, criticism, and suggestions in the provision of feedback comments are imbalanced. This suggests that the current study may have implications for supervisors to further reinforce the expressive approval feedback functions while sustaining the expressive-disapproval (criticisms) and expressive suggestion in a balanced manner. This is because the expressive approval feedback function may encourage and improve supervisees writing competence (Akin-Little et al., 2004) and enhance good relations between supervisors and supervisees.

Concerning thesis supervisors' feedback focus, the study concluded that the feedback comments the supervisors provide to their supervisees were largely focused on content knowledge, followed by genre knowledge, and then linguistic accuracy and 
appropriateness (forms), respectively. However, it has not been known yet whether the supervisors' focuses of their feedback provisions have been based on the needs and preferences of their supervisees, experiences, missed contents of supervisees' texts, or other indicators.

In conclusion, written feedback thesis supervisors offer to their supervisees is an indispensable source of input for thesis writing (Benesch, 2000; Bitchener et al., 2010; Hyland, 2003; Hyland \& Tse, 2004; Kumar \& Stracke, 2007). Therefore, the findings of this study may give insight into the necessity of supervisory pedagogical scaffolding and communications that might be required of them to supervise EFL supervisees towards independent and competent writers. This suggests that thesis supervisors ought to develop their supervisory competence to facilitate their supervisees' improve academic writing.

\section{Recommendations}

Supervisors are suggested to write their feedback in helpful and constructive ways based on the needs and preferences of their supervisees to enhance their writing competence as feedback is a vital source of input. Besides, supervisors should be cognizant of the power of positive criticism (praise) in inspiring and motivating the supervisees to revise their drafts and improve their writing skills. Therefore, supervisors are recommended to improve the quality of their feedback comments by balancing their criticisms, suggestions, and praise in their comments to develop their supervisees' writing skills. Along with this, teacher education institutions are also suggested to revisit their curriculum for ELT if there are gaps in effective written feedback provisions. Moreover, the universities involved in the current study should develop a manual for implementing and regulating effective written feedback to thesis students' writing. Moreover, the universities are also recommended to organize professional development sessions for the faculty to provide training in offering quality written feedback.

The uptake of the feedback comments has not been studied since how much the supervisees included the feedback comments in their writing is crucial. Therefore, future studies are suggested to examine feedback uptake taking in-text feedback comments offered at various stages. Besides, this study took place on few universities taking feedback comments from only five theses. Further studies on large samples are required to generalize on the issue.

\section{Abbreviations}

EFL: English as a Foreign Language; TEFL: Teaching English as a Foreign Language; SGS: School of graduate studies.

\section{Acknowledgements}

We would like to acknowledge Arba Minch University for funding this study. We would also like to extend our gratitude to the head of the research coordination office at the College of Social Sciences and Humanities (CSSH) for his unreserved facilitation of research funds and timely responses to any query we had. We are also grateful to thesis supervisees and supervisors for their cooperation and help during the data collection.

\section{Authors' contributions}

Both authors read and approved the final manuscript.

\section{Authors' information}

Abate Demissie Gedamu has got both his M.A and Ph.D. in TEFL from Addis Ababa University, Ethiopia. He has taught English for 8 years at different schools and at Arba Minch University for the last 16 years. Besides, he has been supervising M.A and Ph.D. students in TEFL. Besides, he has been conducting studies on various topics in ELT.

Tesfaye Habtemariam Gezahegn has obtained his M. Ed. from the affiliated College of St. Mark and St. John, Exeter University, UK, and his Ph.D. in TEFL from Addis Ababa University. He has been an astute lecturer at various institutions 
and levels for more than 22 years. He has also been supervising M.A and Ph.D. students in TEFL. As well, he has been conducting studies and project works on diverse topics in ELT and ICT in education.

\section{Funding}

This study was funded by Arba Minch University, College of Social Sciences and Humanities, Ethiopia. The fund was used for data collection, data encoding to SPSS, and analysis.

Availability of data and materials

The data used in this work is available for reviewers on request at any time.

Declaration

Competing interests

We declare that there are no competing interests.

Received: 24 May 2021 Accepted: 14 November 2021

Published online: 03 December 2021

\section{References}

Abate, D. (2018). TEFL graduate supervisees' views of their supervisors' supervisory styles and satisfaction with thesis supervision. Iranian Journal of Language Teaching Research, 6(1), 63-74.

Akin-Little, K., Eckert, T., Lovett, B., \& Little, S. (2004). Extrinsic reinforcement in the classroom: Bribery or best practice. School Psychology Review, 33, 344-362.

Benesch, S. (2000). Critical English for academic purposes: Theory, politics, and Practice. Lawrence Erlbaum.

Bitchener, J., Basturkmen, H., East, M. \& Meyer, H. (2011). Best practices in supervisor feedback to thesis students. The National Centre for Tertiary Teaching Excellence: The University of Auckland, New Zealand. Retrieved from https://akoao tearoa.ac.nz/best-practice-supervisor-feedback

Bitchener, J., Basturkmen, H., \& East, M. (2010). The focus of supervisor written feedback to thesis/dissertation students. International Journal of English Studies, 10(2), 79-97.

Carless, D. (2006). Differing perceptions in the feedback process. Studies in Higher Education, 31(2), 219-233.

Chanock, K. (2000). Comments on essays. Do students understand what tutors write? Teaching in Higher Education, 5(1), 95-105.

Creswell, J. W. (2009). Research design: Qualitative, quantitative, and mixed methods approach (3rd ed.). Sage Publications Inc.

Creswell, J., \& Plano Clark, V. (2007). Designing and conducting mixed methods research. Sage Publications.

Ghazal, L., Gul, R., Hanzala, M., Jessop, T., \& Tharani, A. (2014). Graduate students' perceptions of written feedback at a private university in Pakistan. International Journal of Higher Education, 3(2), 13-27. https://doi.org/10.5430/ijhe. $\checkmark 3 n 2 p 13$

Giles, T. M., Gilbert, S., \& McNeill, L. (2014). Nursing students' perceptions regarding the amount and type of written feedback required to enhance their learning. The Journal of Nursing Education, 53(1), 23-30.

Goodman, J. S., \& Wood, R. E. (2004). Feedback specificity, learning opportunities, and learning. Journal of Applied Psychology, 89(5), 809-821. https://doi.org/10.1037/0021-9010.89.5.809

Gul, R., Tharani, A., Lakhani, A., Rizvi, N., \& Ali, K. (2016). Teachers' perceptions and practices of written feedback in higher education. World Journal of Education, 6(3), 10-20. https://doi.org/10.5430/wje.v6n3p10

Hattie, J., \& Timperley, H. (2007). The power of feedback. Review of Educational Research, 77(1), 81-112.

Higgens, R., Hartely, P., \& Skelton, A. (2001). Getting the message across: The problem of communicating assessment feedback. Teaching in Higher Education, 6(2), 269-274.

Holmes, J. (2001). Speech functions, politeness, and cross-cultural communication. In G. Leech \& M. Short (Eds.), An introduction to sociolinguistics (2nd ed., pp. 258-283). Longman.

Hyatt, D. F. (2005). "Yes, a very good point!": A critical genre analysis of a corpus of feedback commentaries on Master of Education assignments. Teaching in Higher Education, 10(3), 339-353.

Hyland, F., \& Hyland, K. (2001). Sugaring the pill: Praise and criticism in written feedback. Journal of Second Language Writing, 10(3), 185-212. https://doi.org/10.1016/\$10603743(01)00038-8

Hyland, K. (2003). Second language writing. Cambridge University Press.

Hyland, K., \& Hyland, F. (2006). State-of-the-art article: Feedback on second language students' writing. Language Teaching, 39, 83-101. https://doi.org/10.1017/S0261444806003399

Hyland, K., \& Tse, P. (2004). Metadiscourse in academic writing: A reappraisal. Applied Linguistics, 25(2), $156-177$.

lqbal, S., Gul, R., Lakhani, A., \& Rizvi, F. N. (2014). Teachers' accounts of their perceptions and practices of providing written feedback to nursing students on their assignments. International Journal of Higher Education, 3(3), 70-80. https://doi. org/10.5430/ijhe.v3n3p70

Kumar, V., \& Stracke, E. (2007). An analysis of written feedback on a PhD thesis. Teaching in Higher Education, 12(4), 461-470. https://doi.org/10.1080/13562510701415433

Lee, I. (2009). Ten mismatches between teachers' beliefs and written feedback practice. ELT Journal, 63(1), 13-22. https:// doi.org/10.1093/elt/ccn010

Leng, K. (2014). An analysis of written feedback on ESL students' writing. Procedia Social and Behavioral Sciences, 123 389-397.

Lindemann, E. (2001). Rhetoric for writing teachers (4th ed.). Oxford University.

Lucero, M., Fernández, M., \& Montanero, M. (2018). Teachers' written feedback comments on narrative texts in elementary and secondary education. Studies in Educational Evaluation, 59, 158-167. 
Magno, C., \& Amarles, A. M. (2011). Teachers'feedback practices in the second language academic writing classrooms. The International Journal of Educational and Psychological Assessment, 6(2), 21-30.

Mulliner, E., \& Tucker, M. (2015). Feedback on feedback practice: Perceptions of students and academics. Assessment \& Evaluation in Higher Education. https://doi.org/10.1080/02602938.2015.1103365

Nurie, Y. (2018). Higher education supervision practices on student thesis writing: Language function and focus of written feedback. International Journal of Teaching and Learning in Higher Education, 30(3), 522-533.

Nurie, Y. (2020). Graduate students' perceived needs and preferences for supervisor written feedback for thesis writing. Journal of Language and Education, 6(4), 153-170. https://doi.org/10.17323/jle.2020.10340

Ogede, O. (2002). Rigor, rigor, rigor, the rigor of death: A dose of discipline shot through teacher response to student writing. In O. Ogede (Ed.), Teacher commentary on student papers: Conventions, beliefs, and practices (pp. 103-118). Bergin \& Garvey.

Saldana, J. (2011). Fundamentals of qualitative research: Understanding qualitative research. Oxford University Press Inc.

Searle, J. R. (1969). Speech acts. Cambridge University Press.

Toledo, R. (2013). Hungry for feedback. PM Network, 27(5), 70

Weaver, M. (2006). Do students value feedback? Students' perception of tutors' written responses. Assessment and Evaluation in Higher Education, 31, 379-394.

Zewdu, E. (2012). An investigation into research culture of Addis Ababa University: The case of TEFL Ph.D. Program of AAU. Unpublished Ph.D. Thesis, AAU: Addis Ababa. https://www.bdu.edu.et/fh/sites/bdu.edu.et

\section{Publisher's Note}

Springer Nature remains neutral with regard to jurisdictional claims in published maps and institutional affiliations.

\section{Submit your manuscript to a SpringerOpen ${ }^{\circ}$ journal and benefit from:}

- Convenient online submission

- Rigorous peer review

- Open access: articles freely available online

- High visibility within the field

Retaining the copyright to your article

Submit your next manuscript at $\gg$ springeropen.com 